www.jmscr.igmpublication.org

Index Copernicus Value: 79.54

ISSN (e)-2347-176x ISSN (p) 2455-0450

crossref DOI: https://dx.doi.org/10.18535/jmscr/v7i6.54

Journal Of Medical Science And Clinical Research

IGM Publication

An Official Publication of IGM Publication

\title{
Activated Autologous Platelet Rich Plasma Therapy in the management of Chronic Non Healing Diabetic Foot Ulcer: One Centre Study from Bangladesh
}

\author{
Authors \\ Dr Md. Ashraful Hoque ${ }^{1}$, Dr Shahnewaz Parvez ${ }^{2}$, Dr Tamanna Afroz ${ }^{3}$ \\ ${ }^{1}$ CMBT, DGHS, Bangladesh \\ ${ }^{2}$ NCDC, DGHS, Bangladesh \\ ${ }^{3}$ Registrar, Apollo Hospitals, Bangladesh
}

\begin{abstract}
Foot ulcers caused by diabetes are most important causes of limb amputations especially lower limb in Bangladesh. Treatment of foot ulcers by conventional way often causes hospitalization for long periods results in huge burden to many people. Use of platelet-rich plasma (PRP) mainly by autologous, that is rich in various growth factors, bear some equivalence to the uniform wound healing. Some studies on human are so far showed the potentiality of PRP as a unique and minimally invasive procedure. We included ten case with non healing diabetic foot ulcers, not responding to conventional treatment modalities, was efficiently treated by PRP.
\end{abstract}

Patients and Methods: This study has included 25 patients of both sex ages from 18 to 60 years, with chronic no healing diabetic foot ulcers. These patients were treated with autologous platelet rich plasma activated by calcium gluconate. Few patients needed 2 times PRP therapy but most of the patients needed just one schedule.

Results: Healing rate was much higher in PRP treated group than conventional group. Improvement was visible after 2 weeks in PRP treated group was because angiogenesis required time to generate.

Conclusion: Activated autologous PRP therapy is more effective than conventional therapy.

Keywords: Platelet Rich Plasma, Autologous, Activation, Calcium Gluconate, Centrifugation, Granulation.

\section{Introduction:}

Diabetes mellitus (DM), usually known as diabetes, is a group of metabolic disorders that is characterized by high levels of blood sugar over a longer period ${ }^{(1)}$. Most common symptoms of high blood sugar includes recurrent urination, increased thirst with hunger ${ }^{(2)}$. If treatment not done in due time, diabetes can cause lots of complications ${ }^{(2)}$. Acute complications can include diabetic ketoacidosis, hyperosmolar hyperglycemic state or death $^{(3)}$. Important long-term obstacles include foot ulcers, stroke, cardiovascular disease, chronic kidney disease and also damage to the eyes.

The pervasiveness of diabetic foot ulcers is approximated to be between $4-10 \%$, and chance of life time prevalence is very high uphill $25 \%$. Those who developed foot ulcers are estimated $12 \%-20 \%$ requires amputations ${ }^{(4,5)}$. These types of ulcers generally become infected and healing is complicate by peripheral neuropathy, atherosclerotic peripheral arterial disease that leads to huge morbidities ${ }^{(6)}$. 
Chronic non healing diabetic foot ulcers are major obstacles in the patients with diabetes. Common site of ulcer is on the sole and frequently stubborn to treat. Still there is no standardized protocol for the treatment of such ulcer. Most common result of this case are amputation of lower limbs that can be avoid by drastic management in earlier stage of treatment.

Conventional treatment options diabetic ulcers includes debridement of dead tissue, controlling infection, care of local area, weight off-loading, stick controlling of blood glucose levels and proper education of patients with their care giver on foot care ${ }^{(4,5)}$ which includes advanced wound care therapies $^{(7)}$.

Emerging cellular therapies like as platelet-rich plasma (PRP) dispense completely newer ulcer management options that could be help to avoid amputation. . PRP is a biological product that can be defined as a portion of the plasma fraction of autologous blood in which platelet concentration above the baseline (before centrifugation). Circulating platelets have lots of complement and also growth factors that contains alpha granules. Secreting growth factors subscribe to the healing process of chronic non healing wounds commencing the repair process by cellular signaling and also regeneration by molecular responses. PRP controls the amount of inflammation, and encourage the role of macrophages and phagocytes.

\section{Inclusion Criteria}

- Age between 18 to 60 years who has minimum one cuteneous ulcers that not improved by conventional treatment after getting 4 weeks of therapy.

- Platelet count $\geq 150,000 / \mathrm{mm} 3$

- Eligible to give written consent.

- H/O no allergy to dressing materials.

\section{Exclusion Criteria}

- Ulcer due to unknown etiology.

- Presence of any kind of active infection.

- Ulcer due to malignancy.

- Platelet count $<150,000 \mathrm{~mm} 3$

- Not able to give written informed consent.

\section{Materials and Methods}

According to the criteria 25 patients were selected from 60 patients for giving autologous PRP therapy. Written informed consent was taken each of them. Blood was drawn from anti cubital area through $19 \mathrm{~g}$ scalp vein needle in $20 \mathrm{ml}$ disposable syringe. Blood was kept in $2.7 \mathrm{ml}$ vacutainer (Cure Medical Tech Co Ltd 1219 liberty ave hillside, NJ07205,USA) containing 3.2\%(1:9) Sodium Citrate. Centrifuge was used Hettich Rotofix 32 A (100 Cummings Center, Ste. 136L Beverly, MA 01915, U.S.A.). First rotation was done $1200 \mathrm{rpm}$ for 10 minutes and second rotation was given $2500 \mathrm{rpm}$ for 5 minutes. Before second centrifugation $10 \%$ Calcium Gluconate was added in a proportion of 1:10 for activation. Prepared activated PRP was given deep intramuscularly around the wound area. Dressing was ensured with $0.9 \%$ normal saline in each day. Follow-up was done regularly.

\section{Results}

Follow-up result is given in figure-1 which showing complete healing was occurred within 28 days if dressing was done regularly.

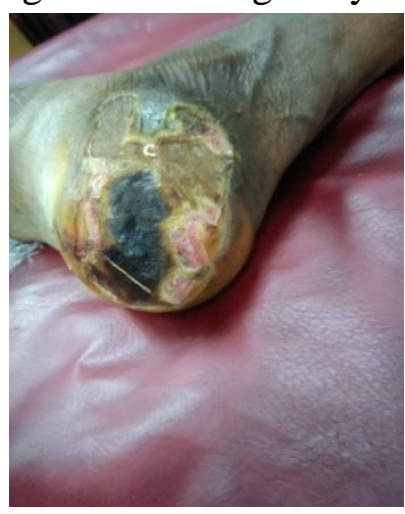

Pic: Before giving activated PRP

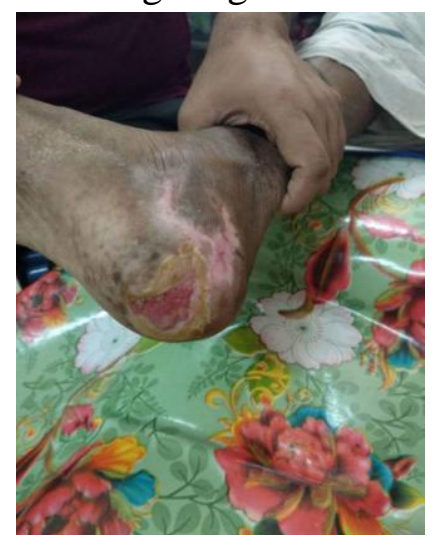

Pic: After giving activated PRP. 


\begin{tabular}{|l|c|c|c|c|c|c|}
\hline $\begin{array}{l}\text { Pt } \\
\text { No }\end{array}$ & Age & Sex & $\begin{array}{c}\text { Wound } \\
\text { size@ 0 } \\
\text { day(cm) }\end{array}$ & $\begin{array}{c}\text { Wound } \\
\text { size@ } \\
\text { day }\end{array}$ & $\begin{array}{c}\text { Wound } \\
\text { size@ 14 } \\
\text { day }\end{array}$ & $\begin{array}{c}\text { Wound } \\
\text { size@ 28 } \\
\text { day }\end{array}$ \\
\hline 1 & 52 & M & 3.2 & 2.1 & 1.6 & Healed \\
\hline 2 & 48 & M & 1.7 & 0.9 & Healed & \\
\hline 3 & 45 & M & 1.9 & 0.7 & Healed & \\
\hline 4 & 59 & F & 2.5 & 1.3 & Healed & \\
\hline 5 & 38 & M & 3.2 & 1.1 & Healed & \\
\hline 6 & 42 & M & 3.4 & 1.9 & 0.9 & Healed \\
\hline 7 & 45 & M & 3.9 & 2.1 & 1.3 & Healed \\
\hline 8 & 43 & M & 4.1 & 2.9 & 1.7 & Healed \\
\hline 9 & 51 & M & 2.9 & 1.4 & 0.8 & Healed \\
\hline 10 & 57 & F & 1.9 & 0.8 & Healed & \\
\hline 11 & 49 & F & 1.7 & 0.9 & Healed & \\
\hline 12 & 50 & M & 1.5 & 0.9 & Healed & \\
\hline 13 & 36 & M & 1.7 & 0.8 & Healed & \\
\hline 14 & 49 & M & 2.8 & 1.7 & Healed & \\
\hline 15 & 54 & M & 2.6 & 1.3 & Healed & \\
\hline 16 & 59 & F & 1.8 & 0.5 & Healed & \\
\hline 17 & 38 & F & 2.3 & 0.5 & Healed & \\
\hline 18 & 48 & M & 3.6 & 1.8 & 0.9 & Healed \\
\hline 19 & 43 & M & 3.9 & 1.7 & 0.8 & Healed \\
\hline 20 & 40 & M & 3.7 & 1.1 & 0.4 & Healed \\
\hline 21 & 60 & M & 3.1 & 1.3 & 0.8 & Healed \\
\hline 22 & 52 & M & 2.3 & 1.7 & 0.9 & Healed \\
\hline 23 & 54 & F & 1.9 & 1.3 & 0.9 & Healed \\
\hline 24 & 57 & M & 1.7 & 1.1 & 0.6 & Healed \\
\hline 25 & 53 & F & 1.1 & Healed & & \\
\hline & & & & & & \\
\hline
\end{tabular}

\section{Discussion}

One of the major cause of mortality and disability caused by macro vascular and micro vascular complication is diabetes mellitus. Lots of complications can occur by diabetes but most common is DFU that usully affecting more than $25 \%$ of people in their life time. It can lead to gangrene and lastly $20 \%$ leads to amputation as because most people do not care about it in the initial stage. Approximately one million amputations done in every year and cause is diabetes. It means in every 30 seconds one diabetic patient loss their limbs worldwide ${ }^{(4)}$. Infected diabetic wound causes huge financial burden to family and also to the country which estimated about 1 billion USD and increases day by day ${ }^{(6)}$.

Conventional treatment options of diabetes are necrotic tissue debridement, wound care, appropriate antibiotic uses, off-loading of the mechanical burden, strict glycemic control and overall increase awareness in the patients and to their family ${ }^{(4,5)}$. Unfortunately, by following every steps sometimes recurrences occur. In case of in these situation other modalities like microsugical flap, VAC therapy applied ${ }^{(5)}$. They are known as advanced wound care therapies ${ }^{(4)}$.

Now a day, cellular therapy as like PRP therapy has play a great role in soft tissue regeneration and a lots of studies have been published regarding successful usage of PRP in DFUs ${ }^{(8-11)}$.

Different studies have already done and reviewed that outlined the use of activated PRP over the wounds. In some studies this is used as adjunct therapy and when healthy granulation tissues arrived surgically covered skin grafts/flaps were given $^{(13)}$. PRP therapy is grounded on the regenerative natures of the platelet for complete healing of such ulcers.

Local infiltration gravitated to assist the natural regeneration of the skin over ulcer/wound. It depends on the chemotactic nature of platelet to tempted the macrophages and begin autophaygocytosis activity to control infection.

PRP restrains a high level of platelets and lots of complement of clotting and also growth factors. 
The secretory proteins accommodate the $\alpha$ granules of platelets that includes platelet-derived growth factor(PDGF), insulin like growth factor (IGF), vascular endothelial growth factor(VEGF) transforming growth factor $\beta$ (TGF- $\beta$ ), platelet factor 4, platelet-derived endothelial growth factor, interleukin-1, fibrinogen, thrombospondin1,platelet-derived angiogenesis factor, , epidermal growth factor, epithelial cell growth factor, osteocalcin, osteonectin, vitronectin and fibronectin $^{(14)}$. Secreting growth factors may play a great role in the healing process of chronic non healing wounds by attracting undifferentiated cells in the area of newly formed matrix and provoking the cell division. PRP may dimished the release of cytokine and ceiling the amount of inflammation, linking with macrophages to ameliorate tissue healing and regeneration, encourage new capillary growth and increase the rate of epithelialization ${ }^{(14)}$. Besides, the activated platelets seemingly have potential antibacterial effects and thereby may support wound healing.

Healing stages typically included firstly suppression of unhealthy granulation, come after by health granulation lining up the defect and jurisdiction of infection and finally epithelization from margins that afterward matured to yield normal skin.

\section{Conflict of interest: No \\ Funding: No}

\section{Acknowledgement}

Centre for Medical Biotechnology, Director General of Hospital Services.

\section{Conclusion}

From our study we can say that autologous activated PRP therapy is a safe, cost effective and very much efficient option for the management of chronic non healing diabetic foot ulcer. But it needs more extensive study for saying that it is the best option in this regards.

\section{References}

1. About diabetes" World Health Organization. Archived from the original on 31 March 2014. Retrieved 4 April 2014.

2. "Diabetes Fact sheet N³12". WHO. October 2013. Archived from the original on 26 August 2013. Retrieved 25 March 2014.

3. Kitabchi AE, Umpierrez GE, Miles JM, Fisher JN (July 2009). "Hyperglycemic crises in adult patients with diabetes". Diabetes Care. 32 (7): 1335-43.

4. Abredari H, Bolourchifard F, Rassouli M, Nasiri N, Taher M, (2015) Health locus of control and self-care behaviors in diabetic foot patients. Med J Islam Repub Iran 26: 283.

5. Kadam D (2016) Microsurgical reconstruction of plantar ulcers of the insensate foot. J Reconstr Microsurg 32: 402-410.

6. Hicks CW, Selvarajah S, Mathioudakis N, Sherman RE, Hines K (2016) Burden of infected diabetic foot ulcers on hospital admissions and costs. Ann Vasc Surg 33: 149-158.

7. Zhang Z, Lv L (2016) Effect of local insulin injection on wound vascularization in patients with diabetic foot ulcer. Exp Ther Med 11: 397-402.

8. Picard F, Hersant B, Bosc R, Meningaud JP (2015) The growing evidence for the use of platelet-rich plasma on diabetic chronic wounds: A review and a proposal for a new standard care. Wound Repair Regen 23: 638-643.

9. Yotsu RR, Hagiwara S, Okochi H, Tamaki $T$ (2015) Case series of patients withchronic foot ulcers treated with autologous platelet-rich plasma. J Dermatol 42:288-295.

10. Mehrannia M, Vaezi M, Yousefshahi F, Rouhipour N (2014) Platelet rich plasma for treatment of nonhealing diabetic foot 
ulcers: A case report. Can J Diabetes 38 58.

11. de Leon JM, Driver VR, Fylling CP, Carter MJ, Anderson C, et al. (2011) The clinical relevance of treating chronic wounds with an enhanced nearphysiological concentration of platelet-rich plasma gel. Adv Skin Wound Care.24 357368.

12. Scimeca CL, Bharara M, Fisher TK, Kimbriel H, Armstrong DG (2010) Novel use of platelet-rich plasma to augment curative diabetic foot surgery. J Diabetes Sci Technol 4: 1121-1126.

13. Driver VR, Hanft J, Fylling CP, Beriou JM; Autologel Diabetic Foot Ulcer Study Group (2006) A prospective, randomized, controlled trial of autologous platelet-rich plasma gel for the treatment of diabetic foot ulcers. Ostomy Wound Manage 52: 68-70.

14. Lacci K.M, Dardik A (2010) Platelet-rich plasma: Support for its use in wound healing. Yale J Biol Med 83: 1-9.

15. Belecki TM, Arendt J, Szczepanski T, Krol W, Wielkoszynski T (2007) Antibacterial effect of autologous platelet gel enriched with growth factors and other active substances: An in vitro study. J Bone Joint Surg Br 89: 417-420. 